\title{
Soluble CD40 Ligand, Plasminogen Activator Inhibitor-1 and Thrombin-Activatable Fibrinolysis Inhibitor-1-Antigen in Normotensive Type 2 Diabetic Subjects without Diabetic Complications
}

\author{
Effects of Metformin and Rosiglitazone
}

\author{
Serkan Yener ${ }^{a} \quad$ Abdurrahman Comlekci $^{a}$ Baris Akinci ${ }^{a}$ Tevfik Demir ${ }^{a}$ \\ Faize Yuksel $^{\mathrm{b}}$ Mehmet Ali Ozcan ${ }^{\mathrm{b}}$ Firat Bayraktar $^{\mathrm{a}}$ Sena Yesil ${ }^{\mathrm{a}}$ \\ Divisions of ${ }^{\mathrm{a}}$ Endocrinology and Metabolism and ${ }^{\mathrm{b}}$ Hematology, Department of Internal Medicine, \\ Dokuz Eylul University School of Medicine, Izmir, Turkey
}

\author{
Key Words \\ Plasminogen activator inhibitor-1 $\cdot$ Soluble CD40 ligand • \\ Thrombin-activatable fibrinolysis inhibitor $\cdot$ Metformin • \\ Rosiglitazone
}

\begin{abstract}
Objective: To evaluate subclinical inflammation and fibrinolysis in low-risk type 2 diabetic subjects and to assess the efficacy of metformin and rosiglitazone in this group. Subjects and Methods: Sixty-one normotensive, normoalbuminuric type 2 diabetic subjects without diabetes-related complications were included in a 4-week standardization period with glimepiride. After the standardization period, 21 subjects were excluded and the remaining 40 were randomly divided into two groups matched for age, gender, body mass index and disease duration. The first group $(n=20)$ received metformin $(1,700 \mathrm{mg} /$ day $)$, the second group $(n=20)$ rosiglitazone ( $4 \mathrm{mg} / \mathrm{day}$ ) for 12 weeks. Patients with low-density lipoprotein-cholesterol higher than $130 \mathrm{mg} / \mathrm{dl}$ at the beginning of the randomization period were treated with simvastatin (maximum dose $20 \mathrm{mg} /$ day). Twenty-three healthy controls were also recruited. Cytokine measurements were performed with ELISA kits. Results: Baseline plasma plasminogen activator inhibitor-1 (PAI-1) level of type 2 diabetic
\end{abstract}

subjects was significantly elevated $(p=0.038)$, but baseline levels of soluble CD40 ligand (sCD40L) and thrombin-activatable fibrinolysis inhibitor-1 (TAFI) antigen did not differ from healthy controls. Twelve weeks of metformin or rosiglitazone therapy did not cause significant changes in sCD40L, PAI-1 and TAFI antigen levels. In simvastatin-treated subjects $(n=9)$ significant reductions of PAI-1 were achieved $(p=0.028)$, while $s C D 40 \mathrm{~L}$ and TAFI-Ag did not differ from baseline values. Conclusion: Our results showed that nonobese diabetic patients at low cardiovascular risk had similar levels of subclinical markers of inflammation and fibrinolysis as matched healthy controls. Neither metformin nor rosiglitazone caused marked changes in $\mathrm{SCD} 40 \mathrm{~L}, \mathrm{PAI}-1$ and TAFI antigen levels. A subset of patients who received simvastatin showed a modest decrease in PAI-1 level and could contribute to beneficial vasculoprotective effect of the drug in type 2 diabetics.

Copyright $\odot 2009$ S. Karger AG, Basel

\section{Introduction}

There is satisfactory evidence demonstrating endothelial activation in early stages of type 2 diabetes $[1,2]$. Normoalbuminuric type 2 diabetic subjects without any

\section{KARGER}

Fax +4161306 1234

E-Mail karger@karger.ch

www.karger.com (c) 2009 S. Karger AG, Basel

$1011-7571 / 09 / 0184-0266 \$ 26.00 / 0$

Accessible online at:

www.karger.com/mpp
Serkan Yener

Dokuz Eylul University School of Medicine, Department of Internal Medicine Division of Endocrinology and Metabolism, Inciralti

TR-35340 Izmir (Turkey)

Tel. +90232412 3701, Fax +90232 279 2267, E-Mail serkan.yener@deu.edu.tr 
complications have impaired vascular reactivity [1], while normotensive and normoalbuminuric patients have endothelial dysfunction despite good glycemic control [2]. Subclinical inflammation and hypofibrinolysis are important factors causing alterations in endothelial system in type 2 diabetes. In these, several factors have been shown to interact with innate immunity and cause subclinical inflammation. Most important of these are insulin resistance, smoking, ethnicity, genetics and nutrition including inappropriate proportions of carbohydrates, fat and protein [3].

Circulating soluble CD40 ligand (sCD40L) is a novel proinflammatory cytokine derived largely from activated platelets and can trigger inflammatory reaction in vascular endothelial cells. Membrane-bound CD40L and sCD40L interact with CD40 molecule that is present on hematopoietic, endothelial and smooth muscle cells, and the release of tissue factor activates platelets which produce more sCD40L thereby perpetuating the inflammatory and prothrombotic environment in the vasculature [4]. In the literature, studies evaluating sCD40L expression in type 2 diabetic patients have discrepant results. While some investigators have reported increased sCD40L levels [5-8], others have not observed a similar association [9-12].

Inhibition of plasminogen activation by plasminogen activator inhibitor-1 (PAI-1) impairs fibrinolysis and promotes thrombosis [13]. PAI-1 is elevated in a variety of clinical situations that are associated with insulin resistance and increased risk of ischemic cardiovascular events like type 2 diabetes [14]. Thrombin-activatable fibrinolysis inhibitor (TAFI) or carboxypeptidase $\mathrm{U}$ is another fibrinolysis inhibitor isolated from human plasma. TAFI-antigen (TAFI-Ag) is a glycoprotein synthesized by the liver that can be activated by thrombin-catalyzed proteolysis to a carboxypeptidase B-like enzyme that inhibits fibrinolysis $[15,16]$. In the literature, the data about TAFI expression in diabetic subjects are limited. Ajjan and Grant [17] demonstrated that in nonobese type 2 diabetic patients TAFI levels were associated with the degree of insulin resistance and glycemic control.

It was previously demonstrated that both metformin and rosiglitazone have some pleiotropic effects, such as reducing microalbuminuria, improving blood pressure and endothelial alterations, besides increasing insulin sensitivity [17]. However, the effects of rosiglitazone or metformin on TAFI-Ag or the effect of metformin on sCD40L have not been evaluated. Furthermore, despite the evaluation of sCD40L, TAFI-Ag and PAI-1 in complicated type 2 diabetes, not much data are available in nor- motensive patients without diabetic complications. Therefore the objectives of this study were to demonstrate the levels of sCD40L, TAFI-Ag and PAI-1 in normotensive type 2 diabetic subjects without diabetic complications and to evaluate the effects of 12-week metformin and rosiglitazone therapy on these proteins.

\section{Subjects and Methods}

Type 2 diabetic subjects (according to American Diabetes Association criteria in 2005) [18] between 30 and 75 years of age, with diagnosis of at least 6 months were included. Exclusion criteria were: hypertension (two consecutive measurements higher than $130 / 80 \mathrm{~mm} \mathrm{Hg}$ ), diabetic retinopathy, diabetic polyneuropathy, history of a cardiovascular and/or cerebrovascular event, history of any chronic disease, pregnancy, child-bearing potential, body mass index (BMI) over $30 \mathrm{~kg} / \mathrm{m}^{2}$, abnormal resting electrocardiography or positive treadmill exercise test, angina pectoris, intermittent claudication, microalbuminuria (daily microalbumin excretion higher than $30 \mathrm{mg}$ ), transaminase levels exceeding 2.5 times normal or serum creatinine levels over $1.4 \mathrm{mg} / \mathrm{dl}$. Patients who were being treated with insulin (or with a history of insulin treatment), anticoagulation drugs, antihypertensive therapy or antiobesity drugs were also excluded. Sixty-one consecutive type 2 diabetic patients and 23 age- and gender-matched healthy controls without any diseases were recruited. Written informed consent was obtained from all participants. Study protocol was approved by the Ethics Committee of the institution.

The study was carried out in two phases: standardization and therapy. During the standardization period, oral antidiabetics were switched to glimepiride with the suitable dose (minimum $1 \mathrm{mg} /$ day and maximum $4 \mathrm{mg} /$ day) regulated according to the patients' plasma glucose levels. Glimepride was preferred for the washout period because of their neutral and/or mild effects on both traditional and nontraditional cardiovascular risk factors [17]. After the 4-week standardization phase, the patients were randomized into two groups: treatment with metformin or rosiglitazone. Twenty patients were randomized to metformin (group M, 10 female subjects, mean age: $53.2 \pm 8.0$ ) and 20 patients were randomized to rosiglitazone (group $\mathrm{R}, 11$ female subjects, mean age: $51.7 \pm 8.1$ ) for 12 weeks.

Twenty-one patients were randomized into two groups. The remaining 21 patients were excluded because of microalbuminuria, hypertension, withdrawal of informed consent or medical need of insulin therapy at the end of the standardization period. Patients with a fasting glucose over $180 \mathrm{mg} / \mathrm{dl}$ continued glimepiride besides metformin or rosiglitazone. Metformin, 1,700 mg/day, was administered in two divided doses (after breakfast and dinner) and the daily rosiglitazone dose was $4 \mathrm{mg}$ and was given before breakfast. The patients $(n=9)$ with low-density lipoprotein cholesterol (LDL-C) higher than $130 \mathrm{mg} / \mathrm{dl}$ at the beginning of the randomization period were treated with simvastatin (maximum dose $20 \mathrm{mg}$ / day). No other antilipidemic drugs were used during the study. The patients were followed for 12 weeks. During follow-up drug doses were not changed and no drugs were added to therapy.

At the beginning and at the end of the randomization periods patients were evaluated after 8 - to 10 -hour fasting. A complete 
medical history was taken. Detailed physical examinations were performed. Height $(\mathrm{m})$, weight $(\mathrm{kg})$ and waist circumference $(\mathrm{cm})$ were measured with subjects in light clothing and without shoes. Blood pressure measurements were recorded using a sphygmomanometer in the sitting position after 5 -min resting. Blood samples were obtained between $8.00 \mathrm{a} . \mathrm{m}$. and $9.00 \mathrm{a} . \mathrm{m}$. in fasting conditions.

Laboratory investigations were as follows: fasting plasma glucose (FPG), 2-hour postprandial glucose (PPG), HbAlc, total cholesterol, high-density lipoprotein cholesterol (HDL-C), triglycerides, serum sCD40L, plasma PAI-1 and plasma TAFI-Ag. Besides, 24-hour urine collections for the detection of microalbuminuria were performed (normal range: 30-300 mg/day). Serum samples for fasting and PPG and lipid parameters were obtained by centrifugation at 2,000 $\mathrm{rpm}$ for $15 \mathrm{~min}$ at room temperature. HbAlc measurements were performed with fresh samples. Serum samples for sCD40L were obtained by centrifugation at 2,000 rpm for $15 \mathrm{~min}$ at $4^{\circ} \mathrm{C}$. For PAI-1 and TAFI-Ag assessments platelet-poor plasma was obtained by centrifugation at 2,000 rpm for $15 \mathrm{~min}$ at $4^{\circ} \mathrm{C}$.

Serum sCD40L, plasma PAI-1 and TAFI-Ag levels were measured using available ELISA kits (sCD40L: Biosource, Nivelles, Belgium; PAI-1: American Diagnostica, Stamford, Conn., USA, and TAFI-Ag: Affinity Biologicals, Ancaster, Ont., Canada). For sCD40L measurements the overall intra-assay and interassay coefficient of variation was 4.0 and $6.8 \%$, respectively. For PAI- 1 the intra-assay coefficient of variation is $4 \%$ and the interassay coefficient of variation is $4.3 \%$. The intra-assay and interassay coefficients of variation for TAFI-Ag are 6\%. FPG, triglyceride, total cholesterol and HDL-C were measured by Roche/Hitachi D/P Modular System Autoanalyzer (Roche Diagnostics, Basel, Switzerland). LDL-C was calculated.

Statistical analysis was performed with SPSS version 11.0 for Windows. Comparisons between groups were determined with Mann-Whitney U test. Comparisons of related samples were assessed with Wilcoxon test. Nonparametric correlations were assessed by Spearman correlation analysis. Multiple regression analysis was used to show independent variables; $p$ value $<0.05$ (two-tailed) was accepted to be significant. We performed three linear regression models to determine the independent factors that could be associated with PAI-1, TAFI-Ag or sCD40L. The independent variables for each model were the same: BMI, waist circumference, HbA1c, total cholesterol, LDL-C and triglyceride. In addition to these independent variables the remaining two cytokines were also added to both models. The results are given as mean values $\pm \mathrm{SD}$.

\section{Results}

The baseline anthropometric and laboratory data of the patients and healthy controls are shown in table 1 . There was no difference for age, gender, blood pressure, waist circumference, waist-to-hip ratio (WHR) and lipid parameters between diabetic subjects and healthy controls. Type 2 diabetic subjects had elevated FPG ( $\mathrm{p}<$ $0.001)$ and higher BMI $(p=0.027)$ when compared with
Table 1. Baseline anthropometric and laboratory characteristics of patients and healthy controls

\begin{tabular}{lccl}
\hline Variables & $\begin{array}{c}\text { T2DM } \\
(\mathrm{n}=40)\end{array}$ & $\begin{array}{l}\mathrm{HC} \\
(\mathrm{n}=23)\end{array}$ & $\mathrm{p}$ \\
\hline Gender, F/M & $21 / 19$ & $12 / 11$ & $\mathrm{NS}$ \\
Age, years & $52.4 \pm 8.0$ & $53.1 \pm 15.6$ & $\mathrm{NS}$ \\
Disease duration, years & $6.8 \pm 6.1$ & - & - \\
SBP, mm Hg & $117.7 \pm 8.7$ & $117.2 \pm 9.8$ & $\mathrm{NS}$ \\
DBP, mm Hg & $77.0 \pm 5.8$ & $75.9 \pm 6.6$ & $\mathrm{NS}$ \\
Body weight, kg & $74.0 \pm 10.6$ & $71.3 \pm 12.8$ & $\mathrm{NS}$ \\
BMI, kg/m & $27.2 \pm 2.4$ & $25.2 \pm 4.4$ & 0.027 \\
Waist circumference, cm & $90.2 \pm 7.8$ & $88.0 \pm 14.9$ & $\mathrm{NS}$ \\
WHR & $0.88 \pm 0.06$ & $0.84 \pm 0.08$ & $\mathrm{NS}$ \\
FPG, mg/dl & $170.5 \pm 45.6$ & $91.2 \pm 10.0$ & 0.000 \\
PPG, mg/dl & $231.9 \pm 95.8$ & - & - \\
HbA1c, \% & $7.7 \pm 1.6$ & - & - \\
Total cholesterol, mg/dl & $197.1 \pm 44.7$ & $190.9 \pm 33.4$ & $\mathrm{NS}$ \\
LDL-C, mg/dl & $116.7 \pm 33.0$ & $111.6 \pm 30.8$ & $\mathrm{NS}$ \\
HDL-C, mg/dl & $51.6 \pm 14.3$ & $53.8 \pm 13.2$ & $\mathrm{NS}$ \\
Triglyceride, mg/dl & $141.7 \pm 71.4$ & $121.1 \pm 44.6$ & $\mathrm{NS}$ \\
UAE, mg/day & $11.8 \pm 7.4$ & - & - \\
sCD40L, ng/ml & $6.81 \pm 3.89$ & $8.54 \pm 4.37$ & $\mathrm{NS}$ \\
PAI-1, ng/ml & $39.99 \pm 10.78$ & $31.76 \pm 11.27$ & 0.038 \\
TAFI-Ag, $\mu$ g/ml & $10.15 \pm 2.73$ & $12.08 \pm 3.07$ & NS \\
\hline & & & \\
\hline
\end{tabular}

Data are expressed as mean values $\pm \mathrm{SD} . \mathrm{T} 2 \mathrm{DM}=$ Type 2 diabetes mellitus; $\mathrm{HC}=$ healthy controls; $\mathrm{SBP}=$ systolic blood pressure; $\mathrm{DBP}=$ diastolic blood pressure; $\mathrm{UAE}=$ urinary albumin excretion; NS = not significant.

healthy controls. Baseline plasma PAI-1 levels of type 2 diabetic patients were significantly higher than those of healthy subjects $(\mathrm{p}=0.038)$. In type 2 diabetic patients baseline levels of sCD40L and TAFI-Ag did not differ from healthy controls.

Twelve-week metformin therapy maintained a significant decrease in FPG $(p=0.018)$ and HbAlc $(p=0.014)$. A slight weight reduction was also observed (from 72.7 to $71.7 \mathrm{~kg}$, and the difference was statistically significant, $\mathrm{p}=0.05$ ). No significant change was observed in BMI, waist circumference, WHR, PPG, lipid parameters, urinary albumin excretion, sCD40L, PAI-1 and TAFI-Ag. In the rosiglitazone group a marked reduction was maintained in FPG ( $\mathrm{p}=0.001)$ and a slight reduction was observed in HbAlc $(p=0.05)$. No significant change was observed in BMI, waist circumference, WHR, PPG, lipid parameters, urinary albumin excretion, sCD40L, PAI-1 and TAFI-Ag. The baseline and 12-week data are summarized in table 2 .

In diabetic patients baseline sCD40L was negatively correlated with total cholesterol $(\mathrm{r}=-0.326, \mathrm{p}=0.043)$, 
Table 2. Baseline and 3-month (after metformin or rosiglitazone) data of groups

\begin{tabular}{|c|c|c|c|c|}
\hline Variables & $\mathrm{M}(0)$ & $\mathrm{M}(3)$ & $\mathrm{R}(0)$ & $\mathrm{R}(3)$ \\
\hline Age, years & $53.2 \pm 8.0$ & & $51.7 \pm 8.1$ & \\
\hline Disease duration, years & $5.9 \pm 4.7$ & & $7.7 \pm 7.4$ & \\
\hline $\mathrm{SBP}, \mathrm{mm} \mathrm{Hg}$ & $119.1 \pm 9.1$ & $118.0 \pm 8.9$ & $116.1 \pm 8.2$ & $115.0 \pm 7.9$ \\
\hline $\mathrm{DBP}, \mathrm{mm} \mathrm{Hg}$ & $77.5 \pm 5.0$ & $78.5 \pm 5.8$ & $76.4 \pm 6.3$ & $75.5 \pm 7.6$ \\
\hline Body weight, kg & $72.7 \pm 11.1$ & $71.7 \pm 10.6$ & $75.3 \pm 10.1$ & $74.7 \pm 9.9$ \\
\hline $\mathrm{BMI}, \mathrm{kg} / \mathrm{m}^{2}$ & $26.7 \pm 2.4$ & $26.4 \pm 2.3^{\mathrm{a}}$ & $27.7 \pm 2.4$ & $27.5 \pm 2.4$ \\
\hline Waist circumference, $\mathrm{cm}$ & $88.9 \pm 8.3$ & $88.5 \pm 7.9$ & $91.5 \pm 7.3$ & $92.3 \pm 6.7$ \\
\hline WHR & $0.88 \pm 0.06$ & $0.87 \pm 0.05$ & $0.89 \pm 0.05$ & $0.90 \pm 0.06$ \\
\hline $\mathrm{FPG}, \mathrm{mg} / \mathrm{dl}$ & $160.1 \pm 42.7$ & $137.1 \pm 44.0^{\mathrm{b}}$ & $180.8 \pm 47.2$ & $143.4 \pm 24.9^{c}$ \\
\hline PPG, mg/dl & $227.5 \pm 90.0$ & $190.1 \pm 69.3$ & $236.3 \pm 103.4$ & $191 \pm 67.1$ \\
\hline HbA1c, \% & $7.5 \pm 1.4$ & $6.6 \pm 1.1^{\mathrm{b}}$ & $7.9 \pm 1.8$ & $7.3 \pm 1.2^{\mathrm{d}}$ \\
\hline Total cholesterol, mg/dl & $204.3 \pm 51.7$ & $217.4 \pm 49.2$ & $190.0 \pm 36.4$ & $206.3 \pm 48.5$ \\
\hline LDL-C, mg/dl & $123.0 \pm 37.8$ & $129.0 \pm 41.6$ & $110.4 \pm 27.0$ & $122.2 \pm 38.1$ \\
\hline $\mathrm{HDL}-\mathrm{C}, \mathrm{mg} / \mathrm{dl}$ & $51.7 \pm 16.5$ & $52.7 \pm 16.4$ & $51.6 \pm 12.2$ & $54.1 \pm 13.0$ \\
\hline Triglyceride, mg/dl & $143.9 \pm 73.8$ & $178.3 \pm 101.1$ & $139.5 \pm 70.8$ & $156.0 \pm 94.0$ \\
\hline UAE, mg/day & $12.4 \pm 7.6$ & $12.5 \pm 6.9$ & $11.2 \pm 7.3$ & $11.6 \pm 6.6$ \\
\hline $\mathrm{sCD} 40 \mathrm{~L}, \mathrm{ng} / \mathrm{ml}$ & $6.00 \pm 3.01$ & $7.55 \pm 4.40$ & $7.58 \pm 4.52$ & $6.36 \pm 3.65$ \\
\hline PAI- $1, \mathrm{ng} / \mathrm{ml}$ & $39.21 \pm 12.91$ & $35.64 \pm 16.35$ & $40.58 \pm 9.18$ & $40.68 \pm 13.24$ \\
\hline TAFI-Ag, $\mu \mathrm{g} / \mathrm{ml}$ & $10.47 \pm 2.56$ & $10.54 \pm 1.91$ & $9.89 \pm 2.90$ & $10.56 \pm 2.96$ \\
\hline
\end{tabular}

Data are expressed as mean values $\pm \mathrm{SD} . \mathrm{M}=$ Metformin; $\mathrm{R}=$ rosiglitazone; $(0)=$ baseline; $(3)=3 \mathrm{rd}$ month; $\mathrm{SBP}=$ systolic blood pressure; $\mathrm{DBP}=$ diastolic blood pressure; UAE = urinary albumin excretion.

${ }^{\mathrm{a}} \mathrm{p}=0.05$ vs. $\mathrm{M}(0) ;{ }^{\mathrm{b}} \mathrm{p}<0.05$ vs. $\mathrm{M}(0) ;{ }^{\mathrm{c}} \mathrm{p} \leq 0.001$ vs. $\mathrm{R}(0) ;{ }^{\mathrm{d}} \mathrm{p}=0.05$ vs. $\mathrm{R}(0)$.

while TAFI-Ag correlated with BMI ( $\mathrm{r}=0.396, \mathrm{p}=0.017)$. No significant correlations of PAI-1 with any other study parameters were observed.

The three linear regression models did not show that any of the confounders had independent associations with baseline cytokine levels.

For the 9 patients (6 in the metformin and 3 in the rosiglitazone group) receiving simvastatin therapy for 12 weeks, the baseline values for sCD40L, PAI-1 and TAFIAg were similar in simvastatin-treated patients $(\mathrm{S}+)$ and simvastatin-naïve patients (S-). In the $\mathrm{S}+$ group significant reductions of PAI-1 were achieved (from 41.08 \pm 15.15 to $33.49 \pm 19.30 \mathrm{ng} / \mathrm{ml}(\mathrm{p}=0.028)$ while $\mathrm{sCD} 40 \mathrm{~L}$ and TAFI-Ag did not differ from baseline values. In simvastatin-naïve subjects no significant change in cytokine levels was observed.

\section{Discussion}

This study showed that normotensive type 2 diabetic patients without diabetic complications had elevated PAI1 and similar sCD40L and TAFI-Ag levels when compared with healthy controls. Metformin or rosiglitazone did not significantly affect these parameters after 12 weeks' therapy. It is well established that hypofibrinolysis promotes atherosclerosis in insulin-resistant subjects. In diabetes, PAI-1 elevation is both a cause and a consequence of insulin resistance [19]. Based on our results it is clear that hypofibrinolysis and the risk of endothelial dysfunction are present even in early stages of diabetes before the development of diabetic complications.

The second fibrinolysis parameter we evaluated was TAFI-Ag. Studies of TAFI levels in diabetes have produced controversial results. While some investigators demonstrated a strong relationship between TAFI and diabetes $[17,20]$, a recent study showed that TAFI levels were not affected by hyperglycemia or insulin resistance [20]. Moreover, Rigla et al. [21] found lower TAFI levels in type 2 diabetic patients and they showed negative correlation between TAFI and glycemic parameters. The lack of diabetic complications or hypertension may lead to similar baseline levels of TAFI in diabetic patients and healthy subjects in our study.

Our data did not confirm previous reports that both metformin $[18,22,23]$ and rosiglitazone [24-26] reduced PAI-1 concentrations. This effect is mainly due to an increase in insulin sensitivity. Short therapy duration, a 
small number of patients or relatively low doses of metformin and rosiglitazone may be responsible for these findings. However, our data confirmed the previous report that no significant change in TAFI levels was observed after pioglitazone treatment [27]. The effect of metformin on TAFI had not been reported previously. First of all, hyperglycemia per se may not be related with TAFI expression in diabetic patients. Hence, metformin or rosiglitazone, despite their beneficial effects on glycemic parameters, did not affect TAFI levels significantly. Secondly, genetic determination of TAFI levels may be predominant. While it has been shown that plasma TAFI concentrations are stable within individuals, they may vary widely between individuals due to genetic determination [28].

Platelets regulate inflammation mainly through the CD40/CD40L pathway. Approximately 95\% of sCD40L in the plasma is of platelet origin. SCD40L has prognostic value in predicting cardiovascular disease as well as fibrinogen or high-sensitivity C-reactive protein [29]. However, interrelations between SCD40L expression and diabetes need to be clarified. In the present investigation, diabetic subjects who had no confounders for diabetic complications or hypertension did not have a significant increase in sCD40L. Our findings reflect the importance of platelet activation and consequently elevated $\mathrm{SCD} 40 \mathrm{~L}$ expression in complicated diabetes or established coronary artery disease. We can suggest that platelet activation is related to the presence of micro- or macroangiopathy or hypertension rather than hyperglycemia per se.

The effect of metformin therapy on sCD40L levels has not previously been evaluated. In our study 12 -week metformin therapy did not cause a significant change in sCD40L levels. In the literature troglitazone and rosigli- tazone were shown to reduce sCD40L levels, while the study evaluating the effect of pioglitazone did not $[6,8]$. In our study the constant levels of sCD40L after rosiglitazone or metformin were an expected finding and probably associated with the similar baseline values between healthy people and diabetic subjects.

We found that simvastatin therapy caused significant reductions in PAI-1 levels in type 2 diabetic subjects. In simvastatin-treated subjects, the reduction achieved in PAI-1 levels may be associated with the regulation of thrombin generation. Furthermore, the effects of lipoproteins on the up-regulation of the generation of PAI-1 from vascular endothelial or smooth muscle cells may be diminished by simvastatin treatment. Lastly, the beneficial effects of simvastatin on inflammation may attenuate PAI-1 generation in endothelial cells.

Our study had several limitations: the reliance on two cytokine measurements for the assessment of hypofibrinolysis, the duration of the therapy and the preferred doses might be inadequate to achieve pleiotropic effects of metformin and rosiglitazone; in addition, strict inclusion criteria might be associated with neutral effects.

\section{Conclusion}

Our results showed that nonobese diabetic patients at low cardiovascular risk had similar levels of subclinical markers of inflammation and fibrinolysis as matched healthy controls. Neither metformin nor rosiglitazone caused marked changes in SCD40L, PAI-1 and TAFI-Ag levels. A subset of patients who received simvastatin showed a modest decrease in PAI-1 level, which could contribute to the beneficial vasculoprotective effect of the drug in type 2 diabetics.

\section{References}

1 Ihlemann N, Stokholm KH, Eskildsen PC: Impaired vascular reactivity is present despite normal levels of von Willebrand factor in patients with uncomplicated type 2 diabetes. Diabet Med 2002;19:476-481.

- 2 Yu Y, Suo L, Yu H, Wang C, Tang H: Insulin resistance and endothelial dysfunction in type 2 diabetes patients with or without microalbuminuria. Diabetes Res Clin Pract 2004;65:95-104.

3 Pickup JC: Inflammation and activated innate immunity in the pathogenesis of type 2 diabetes. Diabetes Care 2004;27:813-823.
-4 Szmitko PE, Wang CH, Weisel RD, de Almeida JR, Anderson TJ, Verma S: New markers of inflammation and endothelial cell activation. Part I. Circulation 2003; 108: 1917-1923.

5 Lim HS, Blann AD, Lip GY: Soluble CD40 ligand, soluble P-selectin, interleukin- 6 , and tissue factor in diabetes mellitus: relationships to cardiovascular disease and risk factor intervention. Circulation 2004; 109: $2524-2528$
6 Varo N, Vicent D, Libby P, Nuzzo R, CallePascual AL, Bernal MR, Fernandez-Cruz A, Veves A, Jarolim P, Varo JJ, Goldfine A, Horton E, Schonbeck U: Elevated plasma levels of the atherogenic mediator soluble CD40 ligand in diabetic patients: a novel target of thiazolidinediones. Circulation 2003; 107: 2664-2669.

-7 Jinchuan Y, Zonggui W, Jinming C, Li L, Xiantao K: Upregulation of CD40-CD40 ligand system in patients with diabetes mellitus. Clin Chim Acta 2004;339:85-90. 
$>$ Marx N, Imhof A, Froehlich J, Siam L, Ittner J, Wierse G, Schmidt A, Maerz W, Hombach V, Koenig W: Effect of rosiglitazone treatment on soluble CD40L in patients with type 2 diabetes and coronary artery disease. Circulation 2003;107:1954-1957.

$>9$ Yngen M, Ostenson CG, Hu H, Li N, Hjemdahl P, Wallen NH: Enhanced P-selectin expression and increased soluble CD40 ligand in patients with type 1 diabetes mellitus and microangiopathy: evidence for platelet hyperactivity and chronic inflammation. Diabetologia 2004;47:537-540.

$\checkmark 10$ Varo N, de Lemos JA, Libby P, Morrow DA, Murphy SA, Nuzzo R, Gibson CM, Cannon CP, Braunwald E, Schonbeck U: Soluble CD40L: risk prediction after acute coronary syndromes. Circulation 2003;108: 1049-1052.

-11 Schonbeck U, Varo N, Libby P, Buring J, Ridker PM: Soluble CD40L and cardiovascular risk in women. Circulation 2001;104:22662268.

-12 Heeschen C, Dimmeler S, Hamm CW, van den Brand MJ, Boersma E, Zeiher AM, Simoons ML: Soluble CD40 ligand in acute coronary syndromes. N Engl J Med 2003; 348:1104-1111.

13 Vaughan DE: PAI-1 and atherothrombosis. J Thromb Haemost 2005;3:1879-1883.

-14 Trost S, Pratley R, Sobel B: Impaired fibrinolysis and risk for cardiovascular disease in the metabolic syndrome and type 2 diabetes. Curr Diab Rep 2006;6:47-54.

- 15 Bajzar L, Manuel R, Nesheim ME: Purification and characterization of TAFI, a thrombin-activable fibrinolysis inhibitor. J Biol Chem 1995;270:14477-14484.
16 Wang W, Boffa MB, Bajzar L, Walker JB, Nesheim ME: A study of the mechanism of inhibition of fibrinolysis by activated thrombin-activable fibrinolysis inhibitor. J Biol Chem 1998;273:27176-27181.

17 Ajjan RA, Grant PJ: Cardiovascular disease prevention in patients with type 2 diabetes the role of oral anti-diabetic agents. Diab Vasc Dis Res 2006;3:147-158.

18 Bailey CJ: Treating insulin resistance in type 2 diabetes with metformin and thiazolidinediones. Diabetes Obes Metab 2005;7: 675-691.

19 Alessi MC, Juhan-Vague I: PAI-1 and the metabolic syndrome: links, causes, and consequences. Arterioscler Thromb Vasc Biol 2006;26:2200-2207.

20 Aso Y, Wakabayashi S, Yamamoto R, Matsutomo R, Takebayashi K, Inukai T: Metabolic syndrome accompanied by hypercholesterolemia is strongly associated with proinflammatory state and impairment of fibrinolysis in patients with type 2 diabetes: synergistic effects of plasminogen activator inhibitor-1 and thrombin-activatable fibrinolysis inhibitor. Diabetes Care 2005;28: 2211-2216.

21 Rigla M, Wagner AM, Borrell M, Mateo J, Foncuberta J, de Leiva A, Ordonez-Llanos J, Perez A: Postprandial thrombin activatable fibrinolysis inhibitor and markers of endothelial dysfunction in type 2 diabetic patients. Metabolism 2006;55:1437-1442.

22 Derosa G, Gaddi AV, Piccinni MN, Ciccarelli L, Salvadeo S, Peros E, Ghelfi M, Ferrari I, Cicero AF: Antithrombotic effects of rosiglitazone-metformin versus glimepiride-metformin combination therapy in patients with type 2 diabetes mellitus and metabolic syndrome. Pharmacotherapy 2005;25:637-645.

-23 Eriksson A, Attvall S, Bonnier M, Eriksson JW, Rosander B, Karlsson FA: Short-term effects of metformin in type 2 diabetes. Diabetes Obes Metab 2007;9:330-336.
24 Bakris GL, Ruilope LM, McMorn SO, Weston WM, Heise MA, Freed MI, Porter LE: Rosiglitazone reduces microalbuminuria and blood pressure independently of glycemia in type 2 diabetes patients with microalbuminuria. J Hypertens 2006;24:2047-2055.

25 Chu JW, Abbasi F, Lamendola C, McLaughlin T, Reaven GM, Tsao PS: Effect of rosiglitazone treatment on circulating vascular and inflammatory markers in insulin-resistant subjects. Diab Vasc Dis Res 2005;2:37-41.

-26 Albertini JP, McMorn SO, Chen H, Mather RA, Valensi P: Effect of rosiglitazone on factors related to endothelial dysfunction in patients with type 2 diabetes mellitus. Atherosclerosis 2007;195:e159-e166.

-27 Aso Y, Yamamoto R, Suetsugu M, Matsumoto S, Wakabayashi S, Matsutomo R, Takebayashi K, Inukai T: Comparison of the effects of pioglitazone and voglibose on circulating total and high-molecular-weight adiponectin, and on two fibrinolysis inhibitors, in patients with type 2 diabetes. Diabet Med 2007;24:962-968.

28 Juhan-Vague I, Renucci JF, Grimaux M, Morange PE, Gouvernet J, Gourmelin Y, Alessi MC: Thrombin-activatable fibrinolysis inhibitor antigen levels and cardiovascular risk factors. Arterioscler Thromb Vasc Biol 2000;20:2156-2161.

29 Lobbes MB, Lutgens E, Heeneman S, Cleutjens $\mathrm{KB}$, Kooi ME, van Engelshoven JM, Daemen MJ, Nelemans PJ: Is there more than C-reactive protein and fibrinogen? The prognostic value of soluble CD40 ligand, interleukin- 6 and oxidized low-density lipoprotein with respect to coronary and cerebral vascular disease. Atherosclerosis 2006; 187:18-25. 